\title{
Mitigation costs in a globalized world: climate policy analysis with REMIND-R
}

\author{
Marian Leimbach*, Nico Bauer, Lavinia Baumstark, Ottmar Edenhofer
}

August 3, 2009

\begin{abstract}
Within this paper, we present the novel hybrid model REMIND-R and its application in a climate policy context based on the EU target to avoid a warming of the Earth's atmosphere by more than $2{ }^{\circ} \mathrm{C}$ compared to the preindustrial level. This paper aims to identify necessary long-term changes in the energy system and the magnitude of costs to attain such a climate protection target under different designs of the post-2012 climate regime. The regional specification of mitigation costs is analyzed in the context of globalization where regions are linked by global markets for emission permits, goods and several resources. From simulation experiments with REMIND-R it turns out that quite different strategies of restructuring the energy system are pursuit by the regions. Furthermore, it is demonstrated that the variance of mitigation costs is higher across regions than across policy regimes. First order impacts, in particular reduced rents from trade in fossil resources, prevail regardless of the design of the policy regime.
\end{abstract}

keywords: climate policy, energy-economy-environment modeling, energy system, international trade

${ }^{*}$ PIK - Potsdam Institute for Climate Impact Research, P.O. Box 6012 03, D-14412 Potsdam, Germany, Tel. ++49/331/288-2556, e-mail: leimbach@pik-potsdam.de 


\section{Introduction}

Climate change is recognized as a major global threat that the current and the next generations have to deal with. Science is asked to provide evidence for climate change, but also to help policy-making by exploring options of adaptation and mitigation. Model-based quantitative analyses are frequently used in climate policy decision-making. A number of energy-economy-climate models was developed and applied over the last decade - e.g. RICE (Nordhaus and Yang, 1996), MERGE (Manne and Richels, 1996; Kypreos and Bahn, 2003), MiniCAM (Edmonds et al., 1997), IMAGE (Alcamo et al., 1998), G-Cubed (McKibben and Wilcoxen, 1999), MESSAGE-MACRO (Messner and Schrattenholzer, 2000), POLES (Kouvaritakis et al., 2000), AIM (Kainuma et al., 2003), DEMETER (Gerlagh and van der Zwaan, 2003), MIND (Edenhofer at al., 2005), FAIR (den Elzen and Lucas, 2005), E3MG (Barker et al., 2006), WITCH (Bosetti et al., 2006), Imaclim-R (Crassous et al., 2006). For an overview see Sanstad and Greening (1998) and Kahouli-Brahmi (2008). The survey given by Kahouli-Brahmi (2008) indicated that most recently major progress was made in modeling endogenous and induced technological change (see also Löschel, 2002; Edenhofer et al., 2006).

The energy sector is a key sector for technological change as well as for promising mitigation strategies. A portfolio of different technological options and a flexible investment dynamic are crucial in transforming the energy system in a climate-friendly way. Technological potentials differ between regions and mitigation costs depend on regional interactions. Only few models take all these aspects into account. Bottom-up models can provide a detailed description of energy technologies. However, they have been criticized for ignoring economic feedbacks of different energy pathways (Hourcade et al., 2006). Top-down models, in contrast, have addressed macroeconomic consequences of energy and climate policies. While also representing some microeconomic realism (e.g. captured in consumer preferences and substitution elasticities) in the absence of structural breaks in the development and consumption styles, top-down models are poor in technological explicitness.

We present the hybrid model - REMIND-R - that couples a macroeconomic system module with a highly disaggregated energy system module (cf. Bauer et al., 2008). Hybrid models bridge the gap between conventional top-down and bottomup modeling approaches (Hourcade et al., 2006) and become the preferable tool in supporting policy-making. Frei et al. (2003) stress the importance of hybrid 
models and its dynamic formulation in providing consistent policy analyses, in particular due to the endogenous formulation of investment decisions which allows for an explicit description of evolving specific capital stocks and technology mixes. In REMIND-R, mitigation costs estimates are based on technological opportunities and constraints in the development of new energy technologies. Most essential, technological change in the energy sector (as represented in bottom-up models) is embedded in a macroeconomic environment (as represented by top-down models) that by means of investment and trade decisions governs regional development. Altogether, this provides a new level of climate policy decision support and a basis for assessing future climate policy regimes.

Based on the EU target to avoid a warming of the Earth's atmosphere by more than $2^{\circ} \mathrm{C}$ compared to the pre-industrial level, this paper aims to identify the magnitude of costs to attain such a climate protection target under different designs of the post-2012 climate regime. The regional specification of mitigation costs is analyzed in the context of globalization where regions are linked by different global markets for emission permits, goods and resources. Three alternative scenarios of climate policy regimes, based on a different initial allocation of emission rights, have been investigated: (I) contraction \& convergence, (II) intensity target, (III) multi-stage approach. It turns out that the ambitious climate target can be achieved at reasonable costs of around 1.5\% of global GDP. Differences between the regional costs are, however, large. In contrast, mitigation costs across different policy regimes differ less. Nevertheless, for each region single policy regimes are more beneficial than others.

In contrast to previous policy regime analysis (e.g. den Elzen et al., 2005; Vaillancourt et al., 2008) and in following actual discussions on the possibility of very low stabilization, this analysis considers more advanced stabilization targets and provides new technology scenarios. It comes up with a much broader variation of regional mitigation costs based on a detailed description of the regional energy systems and trade linkages.

In section 2, we present the model REMIND-R and discuss its components in some detail, including important assumptions and empirical foundation. Results form REMIND-R simulations for a reference (i.e. business-as-usual) scenario are given in section 3. Main focus of the paper is on the analysis of climate policy scenarios which are presented in section 4 . Section 5 shall provide some conclusions. 


\section{Model description REMIND-R}

REMIND-R is a novel multi-regional hybrid model which couples an economic growth model with a detailed energy system model and a simple climate model (see Figure 1). The individual regions are coupled by means of a trade module. Only few other hybrid models exist that are based on economic growth models - MERGE, Imaclim-R and WITCH are the most wellknown. With MERGE and WITCH, REMIND-R shares the same intertemporal structure, but is distinguished from both by a higher degree of technological resolution in the energy sector. This feature expands the range of mitigation options, which are mainly based on a switch between energy technologies, and compensates for a restricted representation of technological learning. Whereas WITCH is more elaborated in modeling R\&D investments and knowledge spillovers, REMIND-R is more advanced in addressing trade issues. Moreover, the model has no exogenous restrictions that provide maximum growth rates or maximum shares in the energy mix for energy sources or technologies. Such restrictions of the solution space can quite often be found in energy system modeling but are not justified from our point of view. Each restriction can be surmounted by innovation and investment.

A complete technical description of REMIND-R is beyond the length of this paper. We restrict ourself to just a few equations within this section. For a detailed documentation we refer to our website ${ }^{1}$.

The applied version - REMIND-R 1.0 - includes nine world regions:

1. UCA - USA, Canada, Australia

2. EUR - EU27

3. JAP - Japan

4. CHN - China

5. IND - India

6. RUS - Russia

7. AFR - Sub-Saharan Africa (incl. Republic of South Africa)

8. MEA - Middle East and North Africa

9. ROW - Rest of the World (including Latin America, Pacific Asia and Rest of Europe).

\footnotetext{
${ }^{1}$ On http://www.pik-potsdam.de/research/research-domains/sustainable-solutions/remind-code-1 the technical description of REMIND-R and the whole set of input data are available. REMIND-R is programmed in GAMS. The code is available from the authors on request.
} 


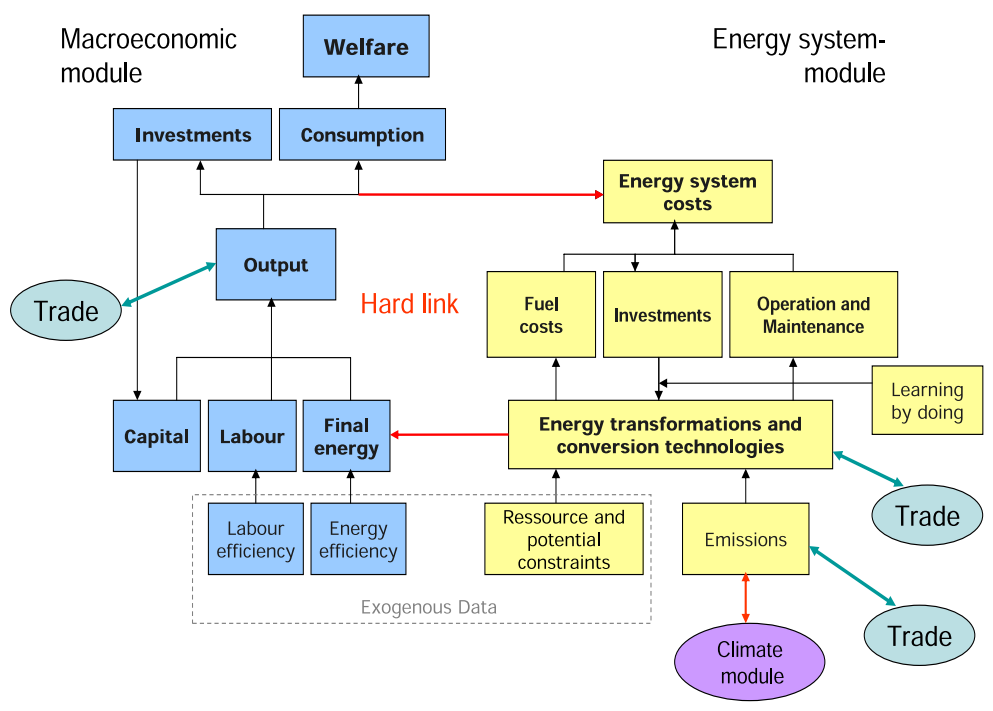

Figure 1: Structure of REMIND-R

The population development of all regions follows an exogenous population scenario (WDI, 2005). World population grows from 6.6 billions in 2005 to 9.0 and 10.0 billions in 2050 and 2100 , respectively.

\subsection{Macro-economy module}

The world-economic dynamics over the time horizon 2005 to 2100 is simulated by means of the macro-economy module in REMIND-R. The time step is five years. Each region is modeled as a representative household with a utility function $U(r)$ that depends upon the per capita consumption. With assuming the intertemporal elasticity of substitution of per capita consumption to be close to 1 it holds:

$$
U(r)=\sum_{t=t_{0}}^{T}\left(\Delta t \cdot e^{-\zeta\left(t-t_{0}\right)} L(t, r) \cdot \ln \left(\frac{C(t, r)}{L(t, r)}\right)\right) \quad \forall r .
$$

$C(t, r)$ represents consumption in time-step $t$ and region $r, L(t, r)$ represents labor (equivalent to population) and $\zeta$ the pure rate of time preference ${ }^{2}$. It is the

\footnotetext{
${ }^{2} \mathrm{We}$ assume a pure rate of time preference of $3 \%$ for the simulation experiments presented in later sections.
} 
objective of REMIND-R to maximise global welfare $W$ that results as a weighted sum of the regional utility functions:

$$
W=\sum_{r}(w(r) \cdot U(r)) .
$$

REMIND-R is run in the cost-effectiveness mode when it is used for climate policy simulations, i.e. climate policy targets are integrated into the model by an additional constraint (e.g. upper bound for temperature increase).

Marco-economic output, i.e. gross domestic product (GDP), is determined by a "constant elasticity of substitution" (CES) function of the production factors labour, capital and end-use energy. End-use energy is the outcome of a nested tree with additional CES production functions (see Figure 2). Each production function calculates the amount of output (intermediate outputs and GDP), $V\left(t, r, v_{\text {out }}\right)$, from the associated factor input amounts $V\left(t, r, v_{i n}\right)$ according to the following quantities:

- parameter $\rho\left(r, v_{\text {out }}\right): \rho$ is calculated from the elasticity of substitution ${ }^{3} \sigma$ according to the relation

$$
\sigma=\frac{1}{1-\rho}
$$

- efficiency parameter $A\left(t, r, v_{i n}\right)$ : It is calculated as the product of an calibrationbased initial value and a time-dependent growth rate parameter.

It holds:

$V\left(t, r, v_{\text {out }}\right)=\left(\sum_{M_{C E S}}\left(A\left(t, r, v_{\text {in }}\right) \cdot V\left(t, r, v_{\text {in }}\right)\right)^{\rho\left(r, v_{\text {out }}\right)}\right)^{1 / \rho\left(r, v_{\text {out }}\right)} \quad \forall t, r, v_{\text {out }}$

The list $M_{C E S}$ assigns the correct input types $v_{\text {in }}$ to each output $v_{\text {out }}$.

The produced GDP of a region is used for the regional consumption $C(t, r)$, investments into the macroeconomic capital stock, $I(t, r)$, all expenditures in the energy system and for the export of goods $X_{G}$. Energy system costs consist of

\footnotetext{
${ }^{3}$ The assumed values for the substitution elasticities (see Figure 2) are comparable to the values assumed by Gerlagh and van der Zwaan (2004, p. 49). Regarding the nesting structure of the energy composite, we tried to replicate the basic structure of energy system services composed of mobile and stationary energy uses. Both are combined by very low elasticities of substitution.
} 


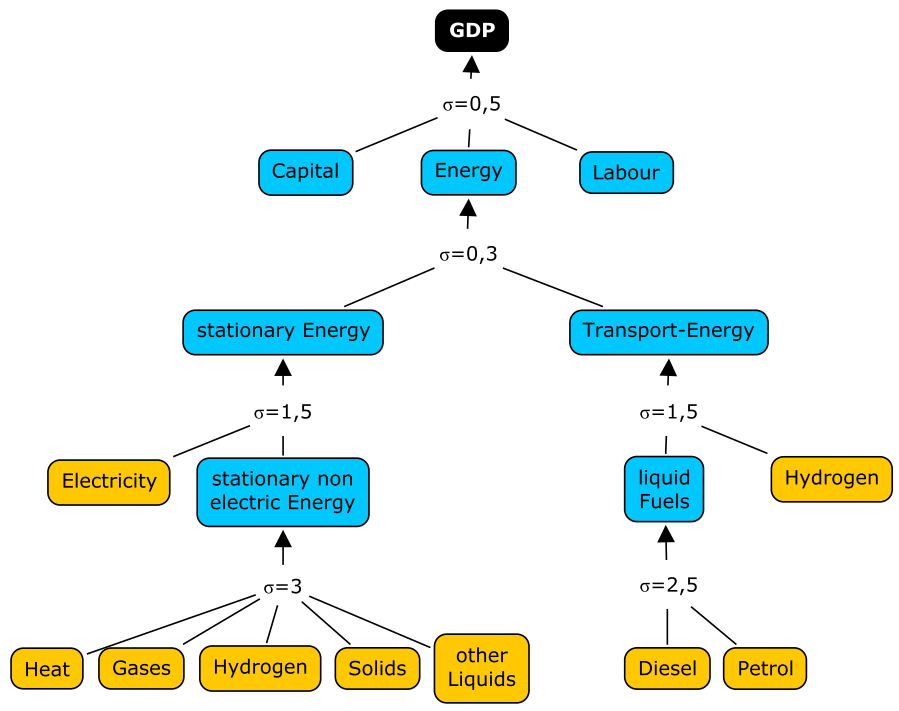

Figure 2: CES production structure in the macro-economic module

fuel costs $G_{F}(t, r)$, investment costs $G_{I}(t, r)$, and operation \& maintenance costs $G_{O}(t, r)$. Imports of the final goods $M_{G}$ increase the available GDP. This yields the following budget equation:

$Y(t, r)-X_{G}(t, r)+M_{G}(t, r) \geq C(t, r)+I(t, r)+G_{F}(t, r)+G_{I}(t, r)+G_{O}(t, r) \quad \forall t, r$

Macroeconomic investments enter a conventional capital stock equation. Changes in the efficiency $A\left(t, r, v_{i n}\right)$ of the individual production factors are given by exogenous scenarios. For all energy production factors, efficiency change rates are defined in relation to labor productivity changes, assuming e.g. that efficiency improvement for the production factors hydrogen and electricity is higher than labor productivity growth, but for solids and heat it is lower. The rate of labor productivity change itself is based on a time profile which starts on a level which is in accordance to empirical data (PWT, 2007) and ends at a predefined level which amounts to $1.2 \%$ for the developed world regions, $2.0 \%$ for China, Russia and ROW, and $2.5 \%$ for Africa, India and MEA. The transition from the initial to the final growth rate level also differs between regions. The resulting pattern of economic growth (see Figure 4 in section 3) resembles that found in the literature (e.g. 
Guest and McDonald, 2007, p. 868; Riahi et al., 2007, p. 901). It is characterized by decreasing growth rates and longsome convergence of per capita incomes.

\subsection{Energy system module}

The energy system module (ESM) of REMIND-R comprises detailed technical and economic aspects of energy transformation. It is based on the energy system structure as it is designed for the single-region model REMIND-G. The ESM depends on the one hand on the macroeconomic output which is used for financing investments into energy transformation capacities, fuel costs spendings and expenditures for operation and maintenance (see eq. 4). It provides on the other hand final energy $P_{f}\left(t, r, e_{s}, e_{f}, c\right)$ that is used in the macro-economy:

$$
V\left(t, r, e_{f}\right)=\sum_{M_{s \rightarrow f}} P_{f}\left(t, r, e_{s}, e_{f}, c\right) \quad \forall t, r, e_{f}
$$

The list $M_{s \rightarrow f}$ describes the possible combinations of secondary energy $e_{s}$, final energy $e_{f}$ and technology $c$. Similar energy balances that equate production and demand exist for primary and secondary energy. Leontief-type technologies with efficiency parameter $\eta$

$$
\sum_{d} \eta(t, r, c, d) \cdot D_{p}\left(t, r, e_{p}, e_{s}, c, d\right)=P_{s}\left(t, r, e_{p}, e_{s}, c\right) \quad \forall t, r
$$

transform primary energy $D_{p}$ into secondary energy $P_{s}$ based on different vintages $d$. Analog equations apply for the transformation of secondary energy into secondary energy of higher value and of secondary into final energy. More than 50 different transformation technologies are represented in the ESM (see Table 1 for an overview on primary-energy-transforming technologies). Technologies are bound to capacities which constrain the production potential. New capacities can be built up by investments. The efficiency of some technologies is assumed to increase over time, but only for new vintages.

Multiple primary energy sources are available in the ESM. There are renewable primary energy sources that can be used in each period without changing the costs of utilization in subsequent periods. However, they cannot be used unboundedly. Region-specific and energy source-specific potentials are defined here. In addition, the potentials are classified into different grades which, as a result of optimisation, leads to a gradual extension of the use of renewable energy sources. 


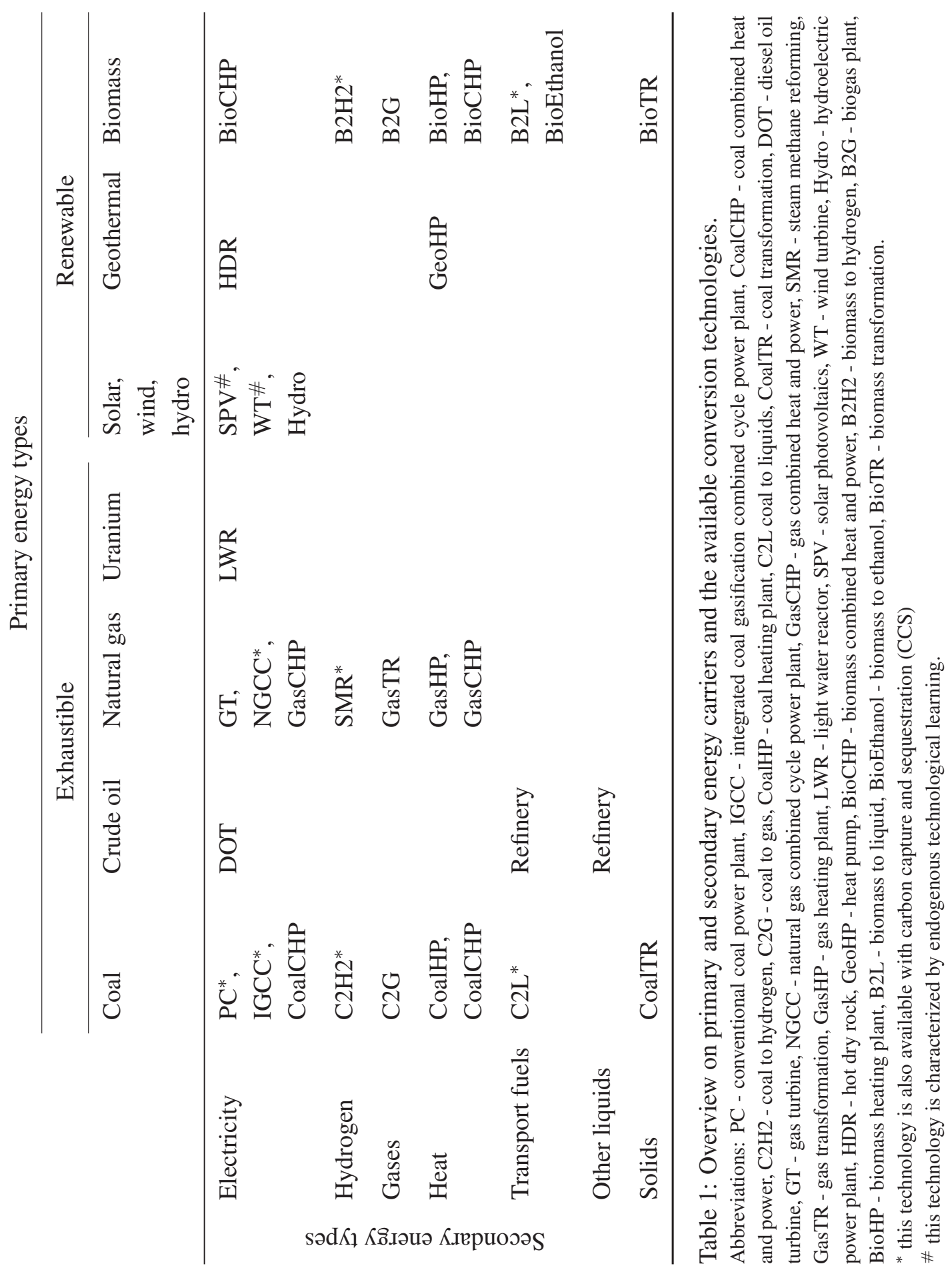


Besides, there are exhaustible primary energy sources where the costs rise with increasing cumulative extraction region-specifically and energy source-specifically. Our assumption on the scarcity of exhaustible resources is based on data from ENERDATA $^{4}$. Figure 3 shows the reserves of exhaustible primary energy carriers differentiated by energy sources and regions. Table 2 shows the cost parameters for the exhaustible resources. For all regions and energy types, the respective extraction curve starts at the initial extraction costs. The extraction costs at reserve limit are exactly met, when extraction reaches the reserve limit. The initial extraction costs and those at the reserve margin are connected by a quadratically increasing function. Extraction of the primary energy types beyond the reserve limit can be extended, but the extraction costs continue to follow the quadratic increase. The assumptions on extraction costs of fossil resources are at the bottom edge of estimations to be found in the literature (e.g. Rogner, 1997).

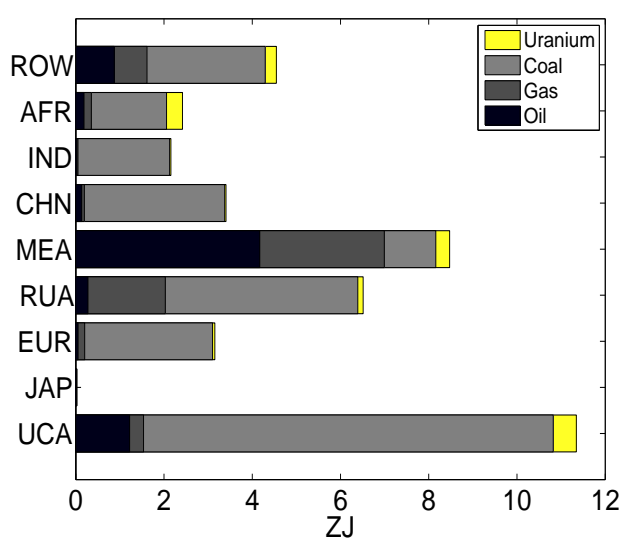

(a) Countries

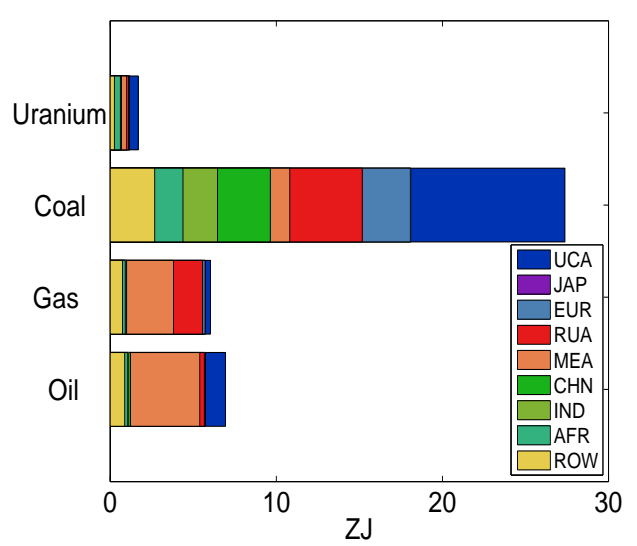

(b) Energy carriers

Figure 3: Overview on reserves of exhaustible primary energy carriers

As for exhaustible primary energy sources, the use of fossil energy leads to $\mathrm{CO}_{2}$ emissions, while the application of carbon capture technologies can contribute to a strong decrease of $\mathrm{CO}_{2}$ emissions. The model considers that captured $\mathrm{CO}_{2}$ needs to be transported and compressed prior to injection. Storage is assumed to be in geological formations only. However, space in geological formations is

\footnotetext{
${ }^{4}$ Most recent data are available on http://www.enerdata.fr/enerdatauk/index.html.
} 
Table 2: Overview on cost parameters of exhaustible primary energy carriers.

\begin{tabular}{|c|cccc|}
\hline & Coal & Oil & Natural gas & Uranium \\
\hline \hline Initial extraction costs [\$US per GJ] & 1.5 & 3.5 & 3.5 & $30 \frac{\text { \$US }}{\mathrm{kg}}$ \\
Extraction costs at reserve limit [\$US per GJ] & 3.5 & 6 & 6 & $80 \frac{\text { \$US }}{\mathrm{kg}}$ \\
\hline
\end{tabular}

generously measured for all regions. There is leakage in the process of capturing, but by assumption no leakage from sequestered $\mathrm{CO}_{2}$. Transformation technologies which use biomass can also be complemented by $\mathrm{CO}_{2}$ capturing provided that they are used to produce fuels or hydrogen. It is assumed that the production potentials for biomass will increase until 2050 to around $200 \mathrm{EJ}$ where the long-term potential is reached. All these assumptions demand for sensitivity analyses as part of future research.

The investment costs for each technology are the same in each region with the exception of two learning technologies, which are characterized by the fact that their investment costs decrease by a certain percentage (the learning rate) with each doubling of the cumulated capacities. We assume learning rates of $10 \%$ and $20 \%$ for the wind turbine and the solar photovoltaics technology, respectively.

When transforming secondary energy into final energy carriers, real transformation options are of lesser interest, but the distribution infrastructure is of particular importance. Except for hydrogen that can be used for transportation and stationary energy, each secondary energy source will be transformed into exactly one final energy carrier. Losses that occur in the distribution of secondary energy are estimated based on statistical data differentiated by region. In modeling the transport sector, the current model version does not take the use of electricity into account.

\subsection{Trade module}

The model REMIND-R calculates a pareto-optimal solution that corresponds with a global planner solution and/or a cooperative solution ${ }^{5}$. With this approach, it is guaranteed that the necessary emission reductions are carried out cost-efficiently and that all trade interactions are directed at increasing welfare in general and low-

\footnotetext{
${ }^{5}$ In cases without or with internalized externalities (applies to the climate change externality and technological learning), the pareto-optimal solution computed by REMIND-R corresponds also to a market solution.
} 
ering mitigation costs in particular.

Trade is modeled in the following goods:

- Coal

- Gas

- Oil

- Uranium

- Composite good (aggregated output of the macro-economic system)

- Permits (emission rights)

With $X_{j}(t, r)$ and $M_{j}(t, r)$ as export and import of good $j$ of region $r$ in period $t$, the following trade balance equation holds:

$$
\sum_{r}\left(X_{j}(t, r)-M_{j}(t, r)\right)=0 \quad \forall t, j
$$

In order to co-ordinate the export and import decisions of the individual regions, REMIND-R uses the Negishi-approach (cf. Manne and Rutherford, 1994; Leimbach and Toth, 2003). In this iterative approach, the objective functions of the individual regions are merged to a global objective function by means of welfare weights $w$ (cf. eq. 2).

A particular pareto-optimal solution, which in the case of missing externalities corresponds to a market solution, can be obtained by adjusting the welfare weights according to the intertemporal trade balances $B^{i}(r)$ :

$$
\begin{gathered}
B^{i}(r)=\sum_{t} \sum_{j}\left(p_{j}^{i}(t) \cdot\left[X_{j}^{i}(t, r)-M_{j}^{i}(t, r)\right]\right) \quad \forall r, i \\
w^{i+1}(r)=f\left(w^{i}, B^{i}(r)\right) \quad \forall r, i
\end{gathered}
$$

where $i$ represents the iteration index which is skipped from the equations above and $p_{j}^{i}(t)$ represents world market prices derived as shadow prices from eq. 7. The higher the intertemporal trade balance deficit of a region, the more the welfare weight of this region needs be lowered. A lower weight causes: goods exports into this region contribute less but exports from this region contribute more to the global welfare function. This mechanism ensures that regions reduce their intertemporal trade balance deficits. 
With the new set of weights we compute a new solution from which we derive $B^{i+1}(r)$. The welfare weights are iteratively adjusted in a way such that

$$
\sum_{r}\left|B^{i+1}(r)\right|<\sum_{r}\left|B^{i}(r)\right| \forall r, i
$$

and

$$
\lim _{i \rightarrow \infty} B^{i}(r)=0 \quad \forall r,
$$

i.e. the intertemporal trade balance converges to zero for each region.

The trade pattern that will result from model runs is highly impacted by the intertemporal trade balance constraint. Each export of composite goods qualifies the exporting region for a future import (of the same present value), but implies for the current period a loss of consumption. Trade with emission permits works similarly to goods trade. Emission rights are distributed free of charge in the different policy regimes according to different allocation rules. The revenues from the sale of emission rights prove completely advantageous for the selling regions in the way that it generates entitlements for future re-exports of permits or goods. Each unit of $\mathrm{CO}_{2}$ emitted by combusting fossil fuels $E(t, r, c)$ using technology $c$ needs to be covered by emission certificates (either allocated $Q(t, r)$ net of exports $X_{P}(t, r)$ or imported $\left.M_{P}(t, r)\right)$ :

$$
\sum_{c} E(t, r, c) \leq Q(t, r)-X_{P}(t, r)+M_{P}(t, r) \quad \forall t, r .
$$

In REMIND-R, trade in financial assets, represented by trade in the generic good, guarantees an intertemporal and interregional equilibrium. The carbon price and the interest rate can be viewed as the outcome of speculation in forwardlooking asset markets. Models omitting trade in financial assets cannot derive a full intertemporal equilibrium in capital and simultaneously in other markets. In many energy-economy-climate models trade in permits is the only feature of international trade. Welfare improvements by the reallocation of capital or the reallocation of mitigation efforts over regions or time are possible in these models when intertemporal efficiency is violated. In contrast to this model design, REMIND-R derives a benchmark for a first-best intertemporal optimum in all markets.

\subsection{Climate module}

Within the REMIND-R framework, the climate module is represented as a set of equations that restrict the welfare optimization. This version of REMIND-R inte- 
grates a simple climate model (Petschel-Held et al., 1999). For basic model equations as well as for parameter values and initial values see Kriegler and Bruckner (2004).

The climate module considers the impact of greenhouse gas emissions and sulphate aerosols on the level of global mean temperature. The emission of sulphates is directly linked to the combustion of fossil fuels in the energy sector. The radiative forcing of both the non- $\mathrm{CO}_{2}$ greenhouse gases and the $\mathrm{CO}_{2}$ emissions from land use change is taken into account by exogenous scenarios. The former follows the SRES B2-scenario (model AIM), the latter combines the same scenario type with the additional assumption of frozen $\mathrm{CH}_{4}$ and $\mathrm{N}_{2} \mathrm{O}$ emissions after 2005. The climate sensitivity - as the most important parameter of the climate module - is set to $2.8^{\circ} \mathrm{C}$. In section 4.6 we briefly discuss the sensitivity of mitigation policies on this parameter.

\section{Reference scenario}

In the reference scenario ("business-as-usual"-scenario), we simulate a development as if climate change has no economically and socially important effects. The world-wide GDP of about 47 trillion $\$ \mathrm{US}^{6}$ in 2005 will increase to 412 trillion \$US in 2100. Figure 4 shows the growth rates of the GDP for each region. China starts with a very high growth rate of $9.3 \%$ which will however decrease to $2.2 \%$ until 2100. India and Africa have the largest growth rates of approximately $3.6 \%$ and $2.9 \%$ at the end of the century, whereas the regions UCA and EUR have a growth rate of $1.2 \%$. While the relative gap between poor and rich regions is becoming shorter, significant differences in the per capita income still exist in 2100.

The development of the energy system is shown in Figure 5. The primary energy consumption ${ }^{7}$ is increasing continuously in the next hundred years from almost $470 \mathrm{EJ}$ in 2005 to more than $1400 \mathrm{EJ}$ in 2100 . A weakening annual increase in primary energy consumption is due to the population scenario, the decreasing growth of demand in the developed countries and the increasing cost of fossil energy sources.

The primary energy mix remains mostly based on fossil energy sources. Whereas

\footnotetext{
${ }^{6}$ Throughout this report, all relevant economic figures (e.g. GDP) are measured in constant international \$US 2003 (market exchange rate).

${ }^{7}$ The primary energy consumption of the renewable energy sources wind, solar and hydro power is put on the same level as the related secondary energy production.
} 


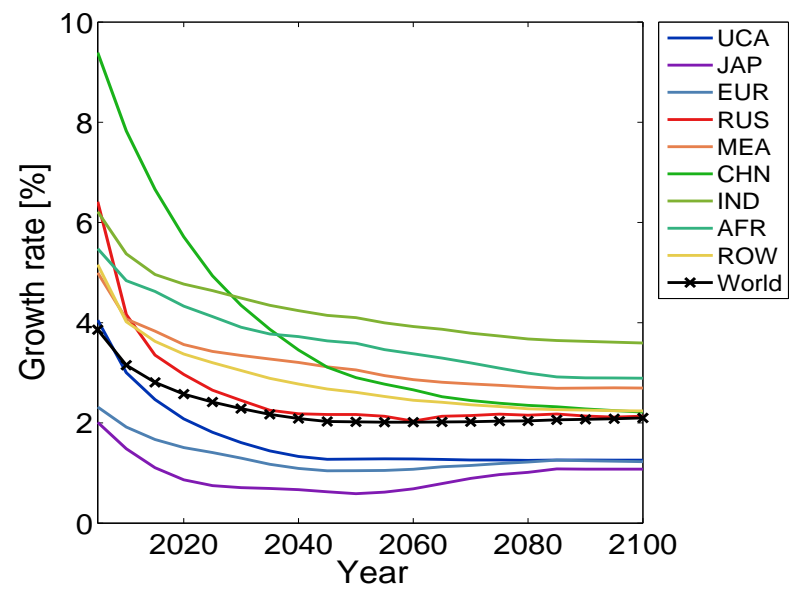

Figure 4: GDP growth rate

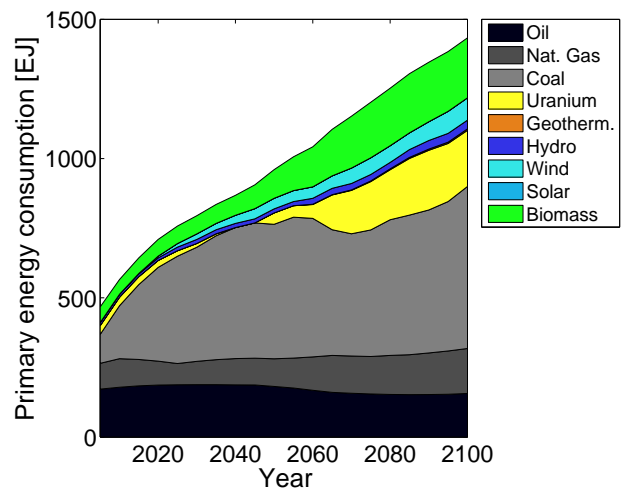

(a) Primary energy

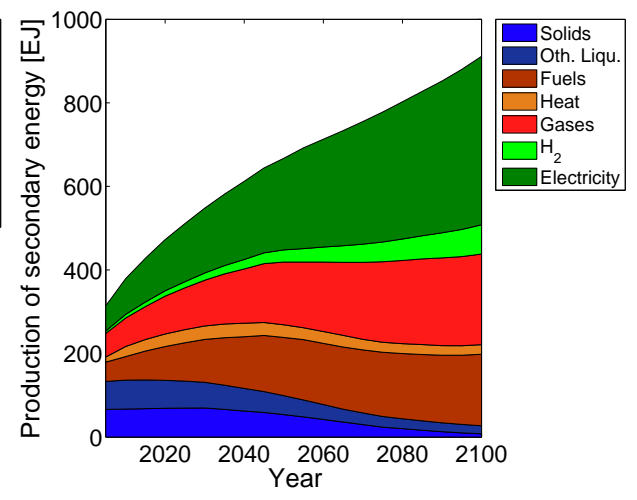

(b) Secondary energy

Figure 5: Global consumption of primary and production of secondary energy sources in the reference scenario

the use of oil and gas remains almost constant, the use of coal is strongly increasing. The economic attractiveness of coal is due to its lower costs, the assumptions of flexible trade and that the use of coal is not subject to any regulations. There, however, is a continuous increase of extraction costs which around the middle of the century makes the use of other energy sources competitive. Hydro energy and 
especially wind energy will increasingly be used. The use of biomass will also increase after 2030, which is due to its increasing availability. Solar energy sources are not employed in the reference scenario; nuclear energy will be used as a considerable supplement for coal at the end of the century. However, as extraction costs of uranium increase quickly, coal consumption is increasing again at the end of the century. Actually, on the regional level, there is a permanent increase in the use of coal in several developing countries, while there is a cutback of coal consumption in the mid of the century and a stabilization on a lower level afterwards in all industrialized countries.

Figure 5(b) shows which secondary energy sources are produced. The secondary energy production will increase to around $900 \mathrm{EJ}$ in 2100; the share of electricity will in particular increase from roughly $19 \%$ to $44 \%$. In contrast, the use of the low-value energy sources "solids" and "other liquids" will decrease.

From the analysis so far it inevitably results that there will be an increase of emissions. This is mostly due to the conversion of coal into electricity. The worldwide emissions amount to approximately $21 \mathrm{GtC}\left(76 \mathrm{Gt} \mathrm{CO}_{2}\right)$ in 2100 (see Figure 6). The increase of emissions is quite high in the early decades - with a doubling of the emissions between 2005 and 2025. The temporary decrease of the emissions around 2060 accompanies the interim reduction of the use of coal. In 2100, approx. $75 \%$ of the emissions in the energy sector originate from the combustion of coal. A share of approx. $15 \%$ and $10 \%$ is allotted to oil and gas, respectively.

Large regional differences in the per capita emissions can be observed. While the industrialized countries increase their per capita emissions until 2025 and keep them on a high level (5-9 tC per year) thereafter, they rise to approx. 2-3 tC in China, India and MEA. Africa remains on a consistently low level with less than 1 tC per capita.

\section{Model analysis of climate policy regimes}

\subsection{Description of the policy regimes}

The following analyses are based on the $2^{\circ} \mathrm{C}$ EU climate policy target. While assuming a cooperative world, within each policy scenario, a global emission path has to be determined which meets the $2^{\circ} \mathrm{C}$ target. Within REMIND-R, the energyrelated $\mathrm{CO}_{2}$ emissions are under the control of the decision-maker only. Exogenous scenarios are applied for the development of other greenhouse gas emissions. In 


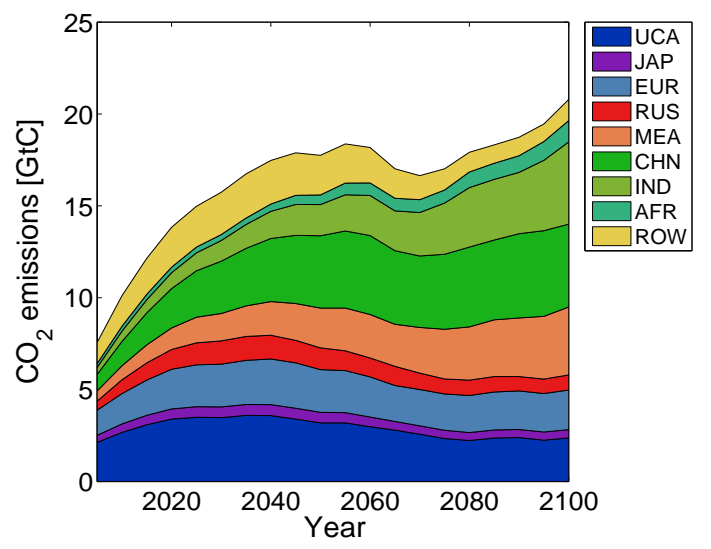

Figure 6: World-wide emissions (energy-related) in the reference scenario

the current model setting, drastic emission reductions would have been provided by the energy sector. While particular technologies generate negative emissions (e.g. the use of biomass in combination with CCS), we assume that on a regional level emissions are positive. Global energy-related $\mathrm{CO}_{2}$ emissions have to be reduced by $50 \%$ until 2035. The atmospheric $\mathrm{CO}_{2}$ concentration reaches its maximum at around $415 \mathrm{ppm}$ in 2030 .

In the analysis of how and at which costs such a reduction path can be achieved, we investigate three different designs of an international cap \& trade system (cf. Höhne et al., 2003). In such a system, tradable emission rights will be allocated to the individual regions as of 2010. The endogenously determined global emission reduction path represents the world-wide available amount of emission rights.

\section{Contraction \& convergence (policy scenario A)}

As of 2050, the same per capita emission rights are allocated in this scenario. By determining these allocations between 2010 and 2050, there is a smooth transition of the regional shares between grandfathering and equal per capita emissions. 2000 is assumed to become the reference year for grandfathering.

\section{Intensity target (policy scenario B)}

In this policy scenario, the shares of the regions on the globally available emission rights correspond to their shares in the world-wide gross product, i.e. each region receives the same emission rights per unit gross domestic product (GDP). In this 
policy scenario, the developed countries are apparently provided with more emission rights than in the other two policy scenarios.

\section{Multi-stage approach (policy scenario C)}

We selected a form of multi-stage approach in which the quantitative reduction obligations of the individual regions depend upon their per capita incomes. The following four stages are distinguished:

$$
\begin{array}{ll}
1^{\text {st }} \text { stage: } & \text { up to } 2,000 \text { \$US per capita and year } \\
2^{\text {nd }} \text { stage: } & \text { up to } 4,000 \text { \$US per capita and year } \\
3^{\text {rd }} \text { stage: } & \text { up to } 8,000 \text { \$US per capita and year } \\
4^{\text {th }} \text { stage: } & \text { more than } 8,000 \text { \$US per capita and year }
\end{array}
$$

Regions of the first stage are practically not obliged to any reductions. They can, however, participate in the emission trade and will be provided with certificates to the amount of their reference case emissions. This is in contrast to alternative definitions of the multi-stage approach (cf. den Elzen et al., 2005). Regions of the second stage will be provided with emission rights to the amount of $0.15 \mathrm{GtC}$ per 1 trillion \$US gross product (GDP). Since a growth of the GDP can be expected as a rule, this stage comprehends an increase of emission rights for the respective regions. Regions of the third stage are obliged to stabilize their emissions, i.e. the certificate amount last allocated in stage 2 is frozen on its level. Regions of the fourth stage have to significantly contribute to the emissions reduction. Their share of emission rights results from deducting the number of certificates used for the regions of stage 1 to 3 from the global amount of certificates. The internal allocation between the regions of stage 4 follows again the above-described contraction and convergence approach.

In the base year, the industrial countries UCA, EUR and Japan are in stage 4. They are presumably quite promptly followed by Russia and China, while China is initially only in stage 2 . MEA is initially also in stage 2 , ROW is in stage 3 , and India and Africa are in stage 1.

\subsection{Technology development and mitigation strategies}

Drastic changes in the energy system are induced by climate policy. The fundamental changes compared to the reference scenario can be summarised in five options for action: 
1. Reduction of the entire energy consumption.

2. Immediate expansion of renewable energy technologies for the production of high-value energy sources; expansion of nuclear energy.

3. Application of $\mathrm{CO}_{2}$ capturing and sequestration (CCS) for the conversion of gas and coal into electricity as well as biomass into hydrogen and fuels.

4. Reducing the production of fuels and gases, since technical avoidance options are less efficient here.

5. Reducing the production of low-value energy sources solids and other liquids.

The technological development is the same in all policy scenarios. This is due to the separability of efficiency and distribution which applies to models of the general equilibrium type in the absence of market imperfections. This seperability can be derived from the Second Fundamental Theorem of Welfare Economics (cf. Mas-Colell and Whinston, 1995, p. 522) or for the case of externalities from the Coase Theorem (cf. Rose and Stevens, 1993). In general, there exists a market price and a trade opportunity that provide an efficient outcome no matter how the property rights are allocated. In our case, due to emissions trading all region will be enabled to follow a unique region-specific optimal technological development path. We renounce to present repeatedly similar development patterns and focus on the results from policy scenario A. This also applies for the trade patterns in the next section.

Figure 7 shows the global consumption of primary and the production of secondary energy. Both will be reduced in relation to the reference scenario. The primary energy consumption reaches approx. $1250 \mathrm{EJ}$ at the end of the century, whereas $1430 \mathrm{EJ}$ were reached in the reference scenario. Secondary energy production increases to roughly $770 \mathrm{EJ}$ in 2100 compared to around $910 \mathrm{EJ}$ in the reference scenario. The most obvious change in the primary energy mix (compared to the reference scenario) is the strong restriction in the use of fossil energy sources and the stronger and earlier expansion in the use of renewable energy sources and nuclear energy. As of 2040, solar energy will also play a role now. The increase of coal consumption in the second half of the century is based on the use of CCS technologies.

Solids and other liquids will already earlier be taken out in secondary energy production. Gas, heat and fuels will be produced to a minor degree. The production of hydrogen and electricity, however, will even increase compared to the reference 
scenario. Electricity production will reach $480 \mathrm{EJ}$ in 2100. Similar results can be found in Weyant (2004, p. 514). The energy mix in global power generation is shown in Figure 8. Wind and nuclear technologies are dominating in the mid term, while the CCS technology options and renewable energies (in particular solar energy) are dominating in the long run.

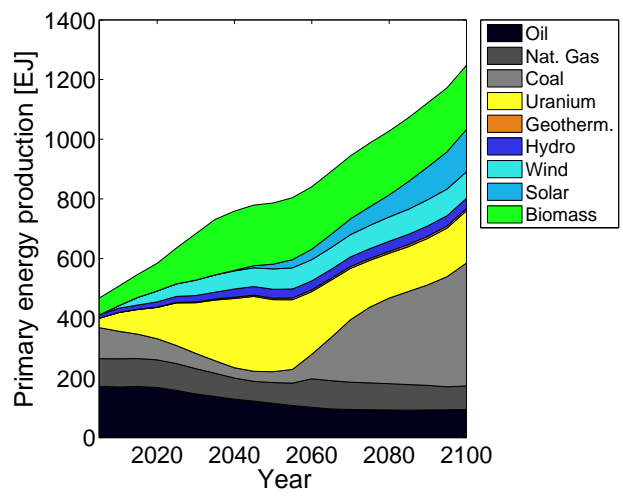

(a) Primary energy

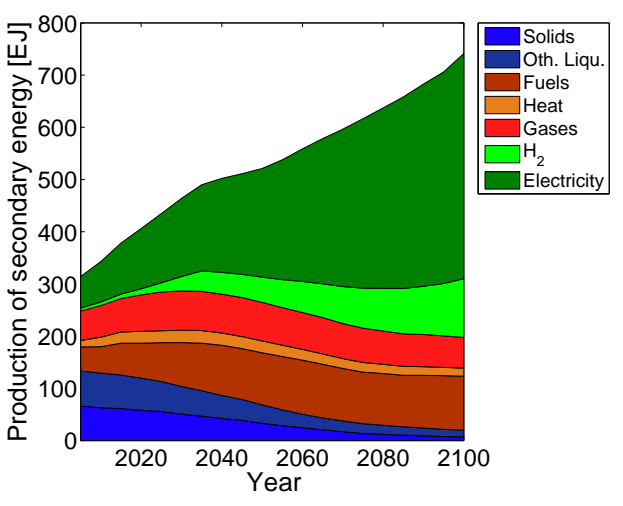

(b) Secondary energy

Figure 7: Global consumption of primary and production of secondary energy sources in policy scenario A

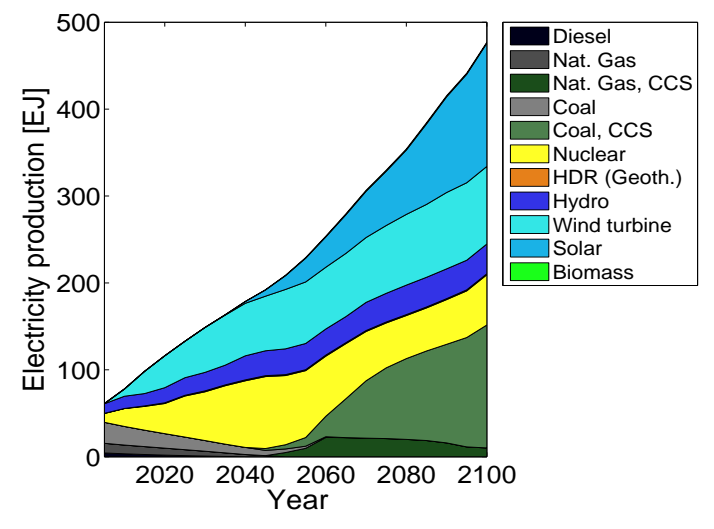

Figure 8: Global electricity production in policy scenario A 
When focussing on the regional energy strategies, it turns out that in the shortterm the increase in primary energy consumption is lower in the developed regions and it is even followed by a decrease in Japan and EUR. The developed regions have in common that the share of fossil fuels is decreasing in the first half of the century, while the share of renewables and nuclear energy increases. While Japan rely on nuclear energy, UCA substitutes nuclear energy technologies as of 2050 by converting coal into electricity with $\mathrm{CO}_{2}$ capturing. The decrease in the consumption of oil and natural gas can partially be compensated in the developed regions by the use of biomass. This is especially obvious in UCA.

While there are some differences in the energy mix of the developed regions, differences are more pronounced when comparing China and India on the one side and Russia, Africa, ROW and MEA on the other side. The latter have high potentials in renewable energy sources that they are going to exploit to a high degree. The largest deviation from the global pattern of energy consumption can be observed for Russia and MEA (see Figure 9). MEA will employ its huge potential of solar. Russia has high potentials in biomass which actually allows them to discontinue the use of natural gas and to export it instead. Biomass is the dominating primary energy source also in Africa.

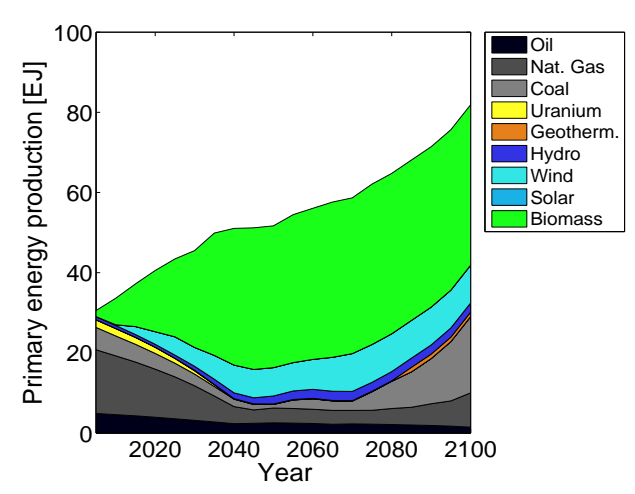

(a) RUS

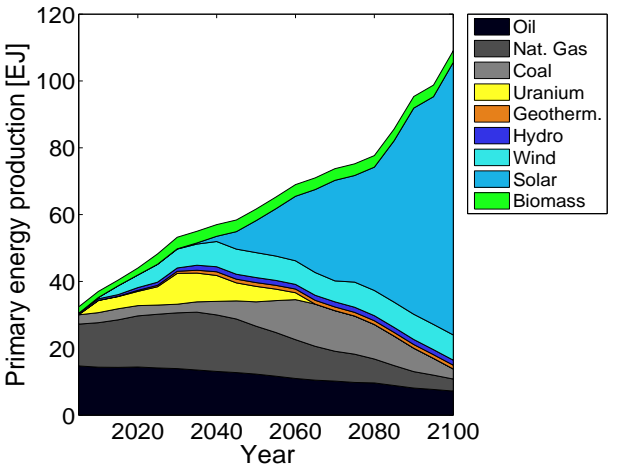

(b) MEA

Figure 9: Regional primary energy consumption in policy scenario A

The development of the energy mix in China and India resembles the global pattern by using nuclear energy technologies and $\mathrm{CO}_{2}$ capturing in coal-fired power plants. $\mathrm{CO}_{2}$ capturing will in addition be used in gas-fired power plants already as 
of 2040 in China. Substantial shares of necessary gas and coal resources will be imported.

On a regional level, results on technological development cannot be compared because there is hardly any literature that provides insights in this detail. Nevertheless, the huge differences in the regional energy mixes are quite remarkable. Results on technological development on a regional level are in general less robust than those on the global level. Shifts in resource trade patterns might change the energy mix (in particular in resource importing regions) without a significant change in regional welfare. If comparing the results on a global level, taking model results from the Innovation Modeling Comparison Project (Edenhofer et al., 2006) as benchmark, the total energy consumption is in line with MESSAGE results. Like MESSAGE, REMIND-R simulates less reduction of energy consumption in the policy scenario compared to the reference scenario than most other models. While the share of renewables is comparable with the share simulated by other models, the high share of biomass is striking. This applies even in the reference scenario and results from the representation of second generation biomass technologies based on most recent findings (e.g. Hamelinck, 2004; Takeshita and Yamaij, 2008). While there are plenty of options to decarbonize the production of electricity, few options exist for the production of fuels and gases. Biomass becomes a serious alternative in this field. Furthermore, REMIND-R exhibits higher shares of nuclear in the short to mid-term and of coal (combined with CCS) in the long-term. Gas and oil is, however, used less compared to most of the other models of the Comparison Project.

\subsection{Trade}

The overall trade structure changes only slightly compared to the reference development in all regions. However, significant changes occur on the energy resource market and the carbon market.

The developed countries use the option of emissions trade and buy permits in considerable amounts. This import, however, is on a value basis hardly visible in the current account. The basis for the current accounts is the present value price of permits which is in a range between $40 \$ \mathrm{US} / \mathrm{tC}$ and $80 \$ \mathrm{US} / \mathrm{tC}$. The nominal values, however, rise quite impressively to a level of more than $500 \$ \mathrm{US} / \mathrm{tC}$ in 2050 and even more than $6000 \$ \mathrm{US} / \mathrm{tC}$ in $2100 .{ }^{8}$ This indicates a very restrictive carbon

\footnotetext{
${ }^{8}$ While for the year 2050, the carbon price here is of the same order of magnitude as the carbon
} 
constraint. The macro-economic effect of emissions trading is slightly higher for the big sellers of emission rights - ROW and above all Africa. This is indicated by Figure 10 which compares the current accounts of Africa in the reference scenario and the policy scenario A. In return to the sale of permits, the import of goods is expanded in Africa. In addition, Africa produces significant export revenues from the trade of uranium. In contrast to the prices of fossil fuels, the price of uranium increases in the policy scenario compared to the reference scenario (by more than $200 \%$ even in the short run).

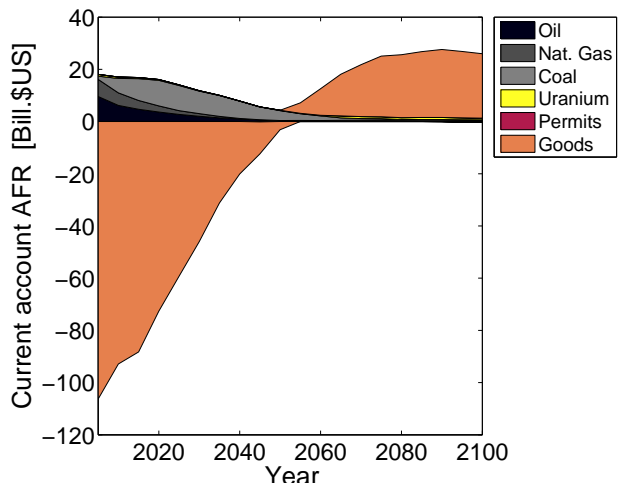

(a) Reference Scenario

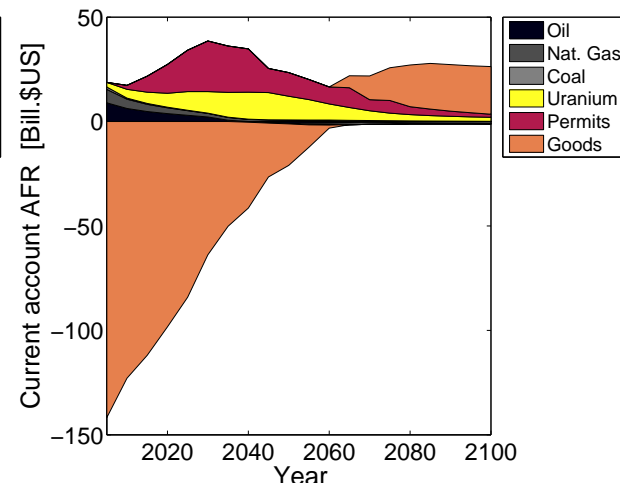

(b) Policy scenario A

Figure 10: Current Account in Africa

In Figure 11, resource trade differences (in physical units cumulated over the century) between the policy scenario and the reference scenario are shown. Negative values represent less trade (either imports or exports) in the policy scenario. In general, trade in fossil resources decreases and trade in uranium increases. Trade with oil decreases significantly (up to more than 30 EJ per year in 2050). Major importers like UCA, EUR, China and India reduce their demands to the account of MEA's exports. Likewise, the trade of coal is substantially reduced. In the reference scenario coal trade increases quickly. As of 2040, trade volumes on the coal market are even higher than on the oil market. In contrast, there is not at all any increase in coal trade in the policy scenario until 2050. Exports from UCA decrease

prices simulated for the less ambitious $450 \mathrm{ppm} \mathrm{CO}_{2}$ stabilization scenario within the Innovation Modeling Comparison Project (cf. Edenhofer et al., 2006, p. 96), it is significantly higher for the year 2100 . 
drastically, while China, the major coal importer, shifts some parts of its imports into the second half of the century. The diffusion of CCS technologies in the policy scenario revitalizes the use and the international trade of coal as of 2050.

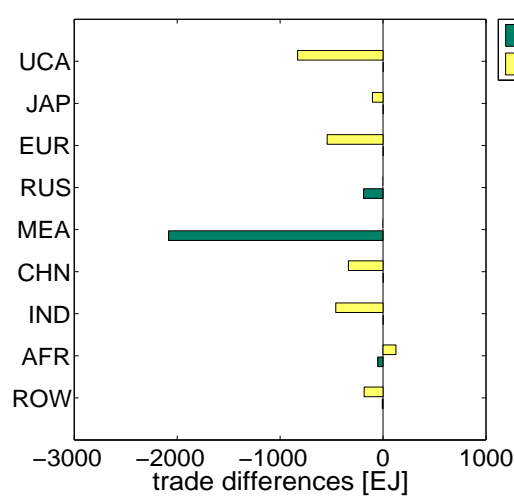

(a) Oil

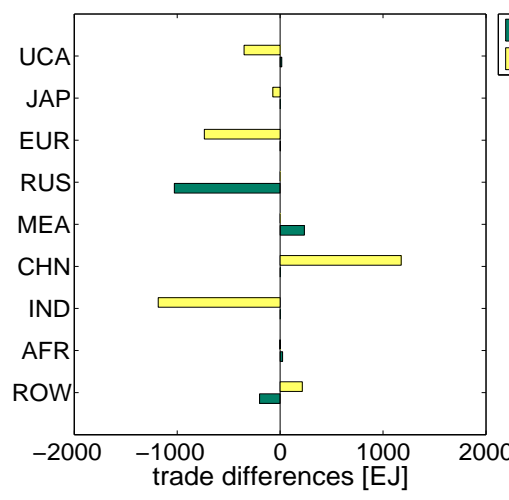

(c) Gas

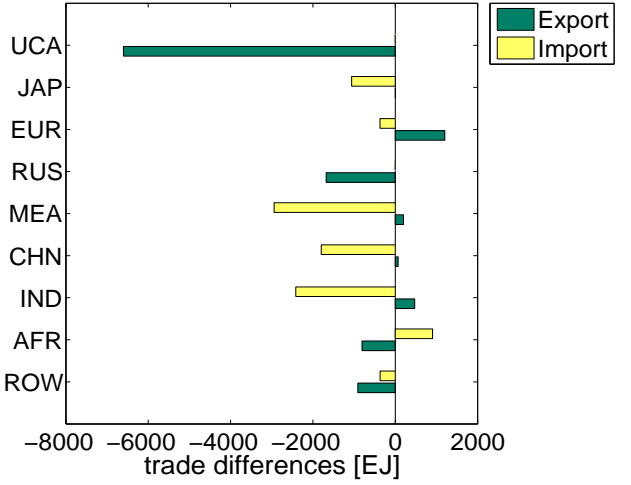

(b) Coal

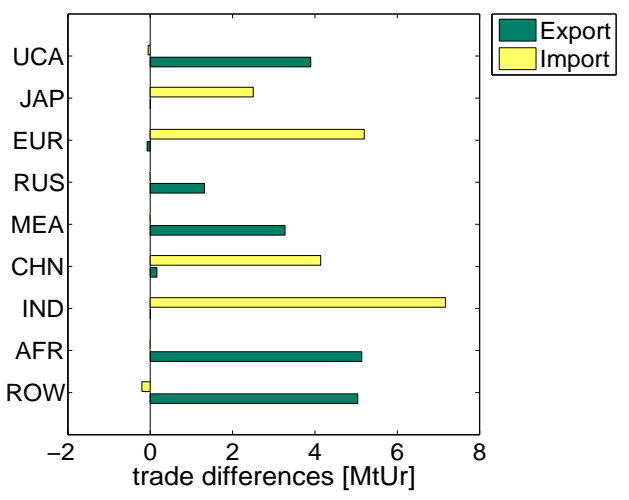

(d) Uranium

Figure 11: Differences in trade between policy scenario A and reference scenario

Due to the better $\mathrm{CO}_{2}$ balance, compared to the other fossil energy sources, the short-term downturn and the overall decrease is significantly smaller in the trade of gas. However, major shifts in the regional shares can be found in the gas market. EUR, UCA and above all India import less, while China increases its imports substantially in the long run. The overall net reduction in gas trading is 
at the expense of Russia. MEA exports less in the mid term but more in the long term.

In line with demand changes on the resource markets we see changes in prices. The oil price in the policy scenario is significantly lower than in the reference scenario (see Figure 12). The difference is somewhat lower for gas and somewhat higher for coal, while the price difference is reversed for uranium.

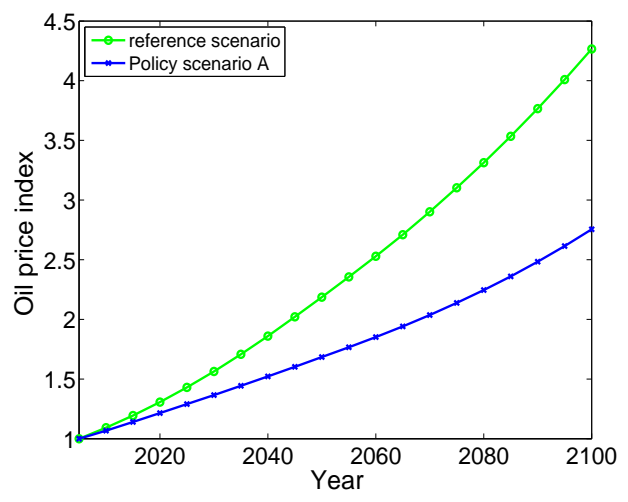

Figure 12: Oil price index in the reference and policy scenario A $(2005=1)$

Worsened terms-of-trade can clearly be expected for the exporters of fossil fuels - MEA, UCA and Russia. Less export revenues have to be compensated by less imports of goods which limits consumption. MEA and Russia are probably more strongly affected than UCA, as resource exports bear a higher share in their current accounts.

Gains and losses from emissions trading, changes in the energy resource market and price-induced terms-of-trade effects have a substantial impact on the mitigation costs (see subsection 4.5). In contrast to the effects from emissions trading, changes in the resource market represent first order impacts that depend on the stabilization target but not on the allocation of permits.

\subsection{Emissions and Emissions Trading}

The pursued stabilization scenario requires a fast and drastic decrease of emissions. Figure 13 shows (exemplarily for policy scenario A) the emissions on the positive side and $\mathrm{CO}_{2}$ capturing on the negative side. It can quickly be seen that the share of oil in the entire remaining emissions is highest. Total emissions from fossil fuels stay above $3 \mathrm{GtC}$ until the end of the century. Most of these emissions are neutral- 
ized by CCS technologies in combination with the use of biomass (green area in Figure 13). The emissions are most rapidly decreasing in electricity production. In this area a lot of $\mathrm{CO}_{2}$ capturing is done, especially when using coal. More than 10 GtC would be captured in 2100 .

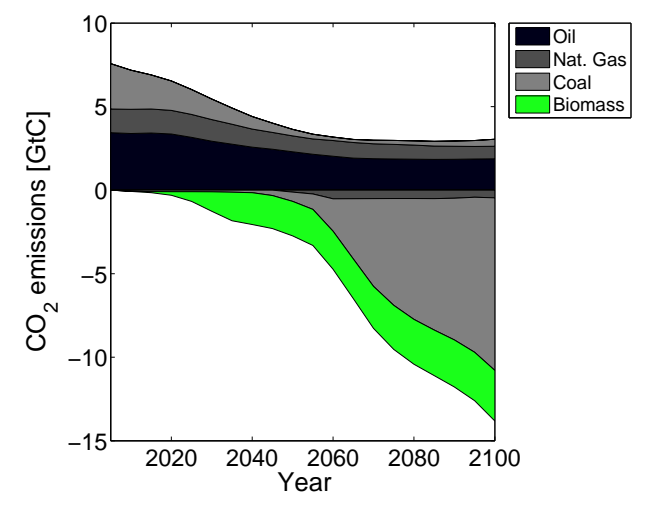

Figure 13: $\mathrm{CO}_{2}$ emissions in policy scenario A differentiated by the use of primary energy sources

\section{Contraction \& convergence (policy scenario A)}

Figure 14(a) shows the permit allocation. The global sum corresponds to the global emission trajectory. Reductions are most drastic between 2025 and 2050. The permit share of the developing world regions and ROW increases drastically. In the case of a missing emissions trading market, the industrialized world regions would need to decrease their per capita emissions to around 5\% of today's level by 2050, MEA, China and ROW to 20-25\%, while India and Africa could still increase their per capita emissions. For both regions it is, however, obviously more favorable not to increase their own emissions but to sell the allocated emission rights profitably. Taking emissions trading into consideration, the reductions are lower in the developed regions. The respective per capita emissions would need to be reduced by approx. $20-35 \%$ in 2025 and by approx. $70-80 \%$ in 2050. Moreover, all regions need to reach per capita emissions of less than $1.2 \mathrm{tC}$ per year in 2050, in 2100 even less than $0.2 \mathrm{tC}$.

The trade of emissions as presented in Figure 14(b) divides the big sellers (ROW, India, China and Africa) and the big buyers (EUR, UCA and MEA). Ini- 


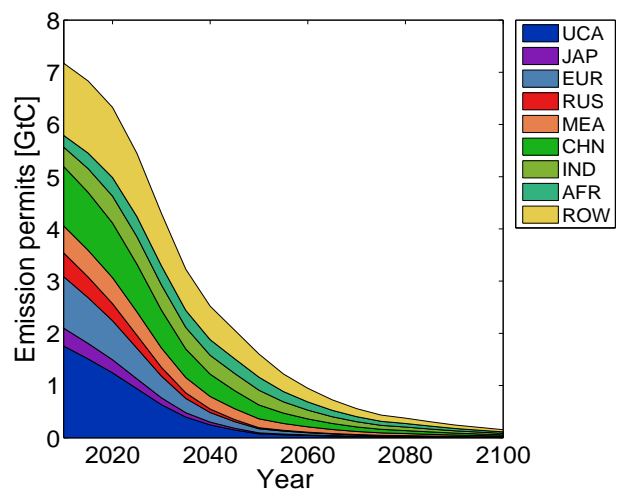

(a) Permit allocation

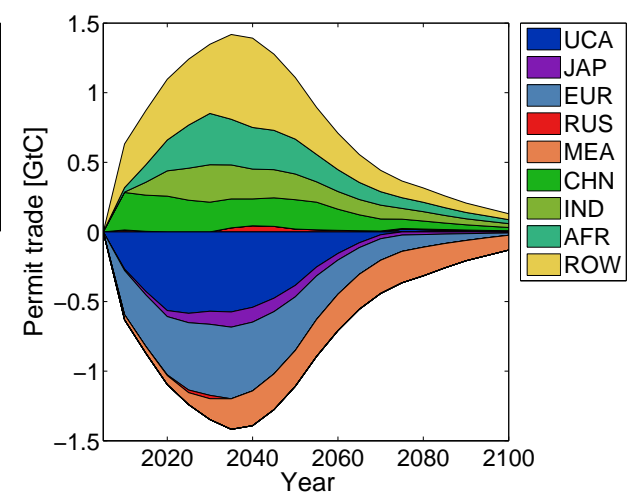

(b) Permit trade

Figure 14: Permit allocation and permit trade in policy scenario A differentiated by regions

tially, permit trading is concentrated on China, ROW, EUR and UCA. The entire trade volume increases to more than $1.4 \mathrm{GtC}$ until 2040 and decreases then to approx. $0.15 \mathrm{GtC}$ until 2100 . With a permit price of more than $300 \$ \mathrm{US} / \mathrm{tC}$, transfers in the order of nearly 500 billion \$US are simulated for the year 2040. As of 2030, the developing regions will sell more than $50 \%$ of the emissions rights allocated to them. This share will in fact rise up to $100 \%$ in Africa, later also in India and Russia. The developed regions will increasingly cover their emissions by buying additional emission rights. Already in 2030, in all industrialized countries more than half of the emissions will be covered by buying additional permits (in UCA even more than $75 \%$ ). In the second half of the century, this share will even further increase, the world-wide available amount of emission rights, however, will decrease to a level of less than $1 \mathrm{GtC}$ and thus the entire trade volume will also decrease.

\section{Policy scenarios $B$ and $C$}

In contrast to the other policy scenarios, the distribution of emission rights according to GDP enables the industrialized countries not only to reduce the share of imported carbon certificates but even to sell their emission rights in a significant magnitude. Initially, Japan, EUR and UCA represent big sellers in the permit mar- 
ket (see Figure 15(a)). In return, all developing regions (in particular MEA and China) and Russia are buying permits. MEA remains the largest importer of emission permits, while China and ROW become major sellers of permits in the mid and long term. The peak in emissions trading of nearly $1.5 \mathrm{GtC}$ appears already in 2010. The yearly trade volume decreases fast to $0.5 \mathrm{GtC}$ in 2030 , and thereafter more slowly to $0.15 \mathrm{GtC}$ in 2100 .

In policy scenario $\mathrm{C}$, the distribution of roles between emission right purchasers and sellers is similar to policy scenario A. However, there is a considerable shift of shares on the sellers' side. In policy scenario C, China's export shares are negligible. Since Africa will raise its per capita income quite slowly (true for all scenarios), it will not reach the stage where substantial emission reductions will become necessary. This is also true for India until 2070. The resultant amount of emission rights for India and Africa restricts on the one hand the allocation of emission rights to other regions and results on the other hand in a quasi monopolistic position of Africa in the sale of emission rights after 2070. In the short to mid term, India dominates the export of emission rights. ROW plays its role as major exporter of permits until 2050 only.

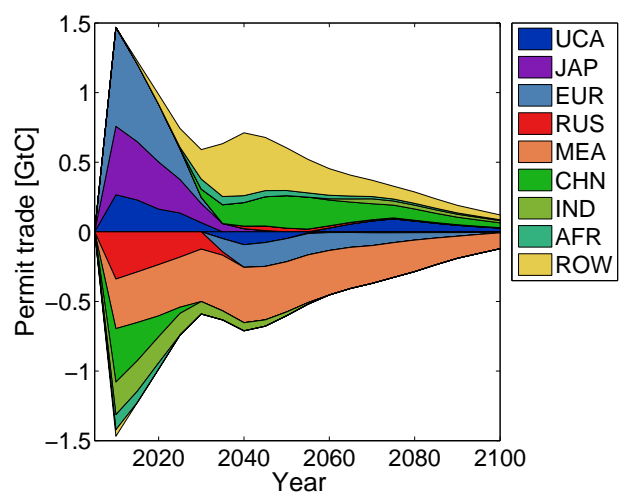

(a) policy scenario B

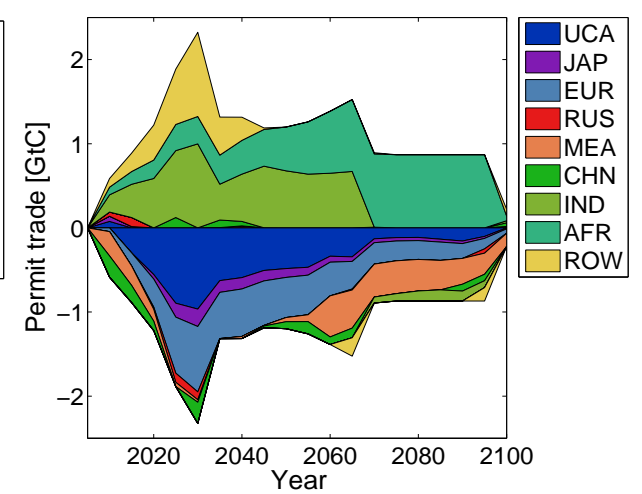

(b) policy scenario $\mathrm{C}$

Figure 15: Permit trade in policy scenarios B and C 


\subsection{Mitigation costs}

All policy scenarios pursue the same stabilization target. Regarding ecological efficiency (i.e. its contribution to climate stabilization), they are almost equal. They are also similar with respect to global mitigation costs which is due to the above mentioned separability of efficiency and allocation. Global average mitigation costs, measured as consumption losses relating to the reference scenario, are between $1.4 \%$ and $1.5 \%$. Global GDP losses are of the same magnitude. ${ }^{9}$

Regional mitigation costs, however, are quite different. Figure 16 provides an overview of the average regional mitigation costs for the three investigated scenarios. Policy scenario A and C have a similar cost structure for UCA, JAP, EUR, MEA and ROW. While the contraction \& convergence scenario is more beneficial for Russia and China, Africa and India benefit significantly from the multi-stage scenario. Policy scenario B has the smallest range in regional mitigation costs. But at the same time, it is also a scenario of extremes. For many regions, it is either the most favorable or the worst scenario. It is most favorable for industrialized countries. The developing regions, on the other hand, need to bear significant mitigation costs. In the light of the distribution of the historical responsibility for the climate problem, this could be a heavy burden in future climate negotiations.

As a robust result, it turns out that the variance of mitigation costs is higher between the different regions than between the different policy scenarios. Obviously, first order impacts prevail regardless of the design of the policy regime. MEA has to bear the highest costs in all scenarios (always more than 9\%). The reconstruction of the global energy system reduces part of the possible rents of this region whose revenues are to a large part derived from selling fossil resources. This is in a slightly milder form also true for Russia (mitigation costs of always more than 5\%). For the three developed regions UCA, Japan and EUR, the costs over the different scenarios develop according to a fixed pattern. The highest mitigation costs among this group can be found in UCA, they are slightly lower in Europe and they are lowest in Japan. Beside the different base level (highest per capita emissions in UCA), the growth pattern is also reflected in this relation. In general it holds: the higher economic growth, the higher the mitigation costs. For all three regions, policy scenario $\mathrm{B}$ is the most favorable one (average mitigation costs amount to $1 \%$ or less). For China, the lowest costs arise in policy scenario A, however, variance of

\footnotetext{
${ }^{9}$ In general, regional GDP losses differ from regional consumption losses. This is due to the effects of international trade.
} 


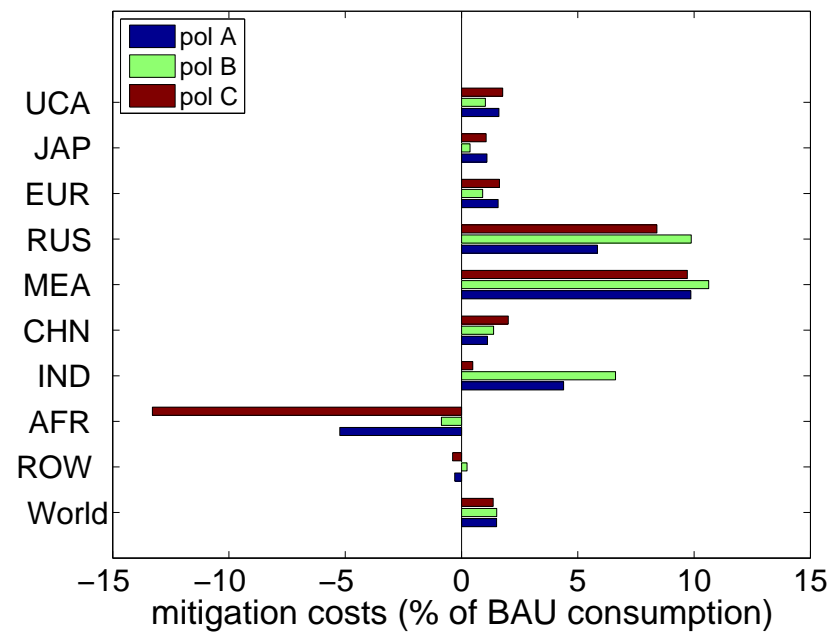

Figure 16: Average mitigation costs

costs between the scenarios is relatively small. The contrary holds for India, where all scenarios but the multi-stage scenario $\mathrm{C}$ are quite expensive. Africa benefits in all policy scenarios, most remarkably in the multi-stage scenario (more than $10 \%$ consumption gains) which is mainly due to the fact that for a long time span Africa is provided with an amount of permits according to its baseline emissions.

The cost differences between the policy scenarios are clearly linked to the transfers on the carbon market. Revenues increases consumption directly, but does not change investment decisions. Emissions trading evens out any changes in relative prices between the different policy scenarios. The fact that mitigation cost differences are relatively low, given the huge differences in permit allocation, may reduce conflicts in the international negotiation process.

\subsection{Climate sensitivity}

While a comprehensive sensitivity analysis is beyond the scope of the paper, we provide some additional insights with respect to the impact of the climate sensitivity parameter. This parameter is considered as one of the most uncertain parameters in Integrated Assessment models. Departing from the default value of $2.8^{\circ} \mathrm{C}$, we run model experiments (exemplarily for policy scenario A) by assuming the climate sensitivity to amount to $2.0^{\circ} \mathrm{C}$ (scenario var 1 ) and $3.5^{\circ} \mathrm{C}$ (scenario var 2). 
Figure 17(a) shows the sensitivity of the global emissions on this assumption. Whereas a low climate sensitivity allows emissions to stay above the current level until 2050, a high climate sensitivity demands for a more drastic reduction of emissions than the default policy scenario A (cf. Figure 14). Within the current setting, REMIND-R is not able to find a feasible solution with a climate sensitivity of $3.6^{\circ} \mathrm{C}$ and higher. Achieving a feasible solution in some of these cases, which requests for an even faster reduction of $\mathrm{CO}_{2}$ emissions than in scenario var 1, will be possible if we allow for idle capacities and negative emissions.

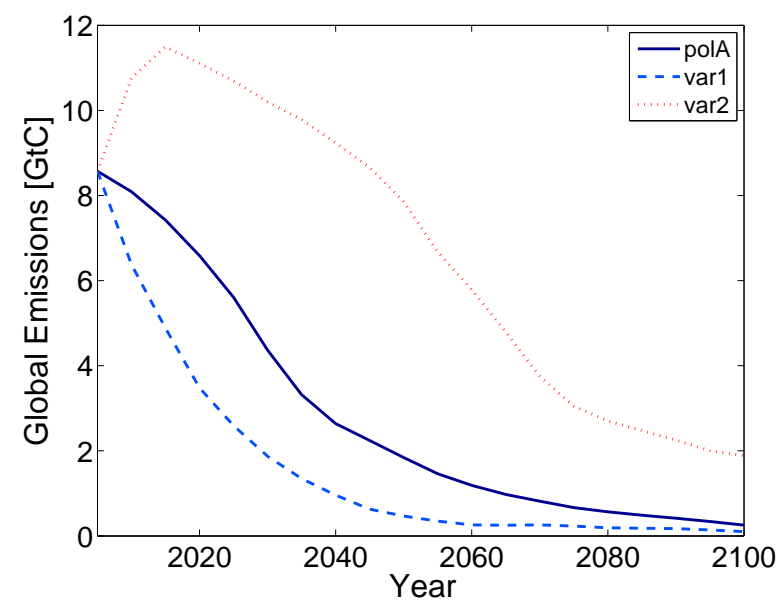

Figure 17: Global emissions for policy scenario A with different climate sensitivities

The drastic emission reduction in the $3.5^{\circ} \mathrm{C}$ climate sensitivity scenario results in an increasing share of solar energy and a complete fade out of coal technologies - even with the CCS option - due to the remaining emissions. Most significant, the total amount of primary energy consumption is reduced - on a global level from around $1250 \mathrm{EJ}$ in 2100 in the default policy scenario A to around $950 \mathrm{EJ}$ in the high climate sensitivity scenario.

The sensitivity of mitigation costs is shown in Figure ??. Mitigation costs more than halve for the low climate sensitivity scenario and more than double for the high climate sensitivity scenario. Both changes indicate a dominant impact of this parameter. The carbon price increases by an order of magnitude in the high climate sensitivity scenario. This would extremely benefit the permit seller and requests for an additional compensation scheme. 


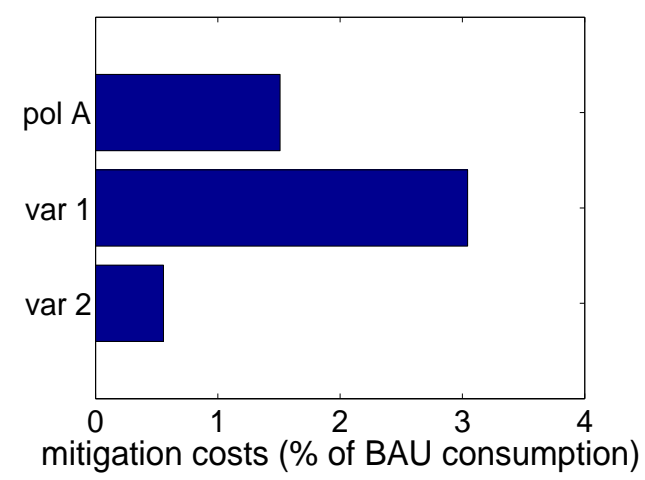

Figure 18: Average mitigation costs for policy scenario A with different climate sensitivities

\section{Conclusions}

This study analyzes climate policy implications in the context of globalization by means of the energy-economy-climate model REMIND-R. In determining regional mitigation costs and the technological development in the energy sector, REMIND$\mathrm{R}$ considers the feedbacks of investment and trade decisions of regions that are linked by global markets. The analyzed policy regimes are primarily differentiated by their allocation of emission rights. Moreover, they represent alternative designs of an international cap \& trade system that is geared to meet the $2^{\circ} \mathrm{C}$ climate target. The following conclusions can be drawn:

- Ambitious climate targets that meet the $2^{\circ} \mathrm{C}$ climate target with high likelihood can be reached with costs amounting to approx. $1.5 \%$ of the global gross product; this roughly confirms cost estimates of low stabilization scenarios from earlier studies based on global models (Edenhofer et al., 2006). This number, however, can halve or double within a quite narrow range of climate sensitivity variation.

- The regional burden of emission reductions considerably varies with the particular designs of a post-2012 climate policy regime; however, the variance of mitigation costs between the regions is higher than between the policy regimes. 
- Regions with high shares in trade of fossil resources (MEA and Russia) bear highest costs, while Africa can considerably benefit from an integration into a global emissions trading system.

The present study analyzes ambitious climate protection scenarios that require drastic reduction policies (reductions of 70\%-80\% globally until 2050). Immediate and multilateral action is needed in such scenarios. Given the rather small variance of mitigation costs in major regions like UCA, Europe, MEA and China, a policy regime should be chosen that provides high incentives to join an international agreement for the remaining regions. From this perspective either the contraction \& convergence scenario (incentive for Russia) is preferable or the multi-stage approach (incentive for Africa and India).

As usual, all results are only valid within the framework of the assumptions made. In the current context, we in particular assume perfect markets and perfect intertemporal foresight. Both slightly tend to decrease the mitigation costs by optimally investing in most promising long-term mitigation measures based on optimal trade flows. However, for the regions with high shares in resources trade mitigation costs could be overestimated by the model due to the fact that the reference scenario accounts for too optimistic trade volumes. Trade losses in the fossilconstrained policy scenario rise consequently. Additional experiments furthermore show that with the assumption of lower fossil resource availability mitigation costs decrease significantly.

From the analysis of the technology development in the energy sector it turns out that the regions follow quite different strategies. However, while the mitigation costs estimates are robust against variations of input parameters, the regional energy mix is sensitive. More research is needed to integrate further technologies (e.g. electric vehicles in the transport sector) and to systematically investigate to which degree and which costs major carbon-free technologies can be substituted by each other. First experiments in this direction indicate that doing without nuclear energy is not costly, but forgoing the CCS option will increase the mitigation costs substantially.

\section{Acknowledgment}

For their help in implementing the REMIND model, we are grateful to our colleagues Michael Lüken and Markus Haller. We also thank the German Federal Environmental Agency for the financial support of this research. 


\section{References}

[1] Alcamo, J., Leemans, R., Kreileman, G.J.J. (1998), Global change scenarios of the 21 st century. Results from the IMAGE 2.1 model. Pergamon \& Elsevier Science, London.

[2] Barker, T., Köhler, J., Anderson, D. and Pan, H. (2006), Combining energy technology dynamics and macroeconometrics: the E3MG model for climate stabilization scenarios. The Energy Journal, Special Issue 2006, 113-133.

[3] Bauer, N., Edenhofer, O., Kypreos, S. (2008), Linking Energy System and Macroeconomic Growth Models. Journal of Computational Management Science 5, 95-117.

[4] Bosetti, V., Carraro, C., Galeotti, M., Massetti, E., Tavoni, M. (2006), WITCH: A World Induced Technical Change Hybrid Model. The Energy Journal, Special Issue 2006, 13-38.

[5] Crassous, R., Hourcade, J.-C., Sassi, O. (2006), Endogenous Structural Change and Climate Targets. Modeling experiments with Imaclim-R. The Energy Journal, Special Issue 2006, 259-276.

[6] Edenhofer, O., Bauer, N., Kriegler, E. (2005), The impact of technological change on climate protection and welfare: Insights from the model MIND. Ecological Economics 54, 277-292.

[7] Edenhofer, O., Lessmann, K., Kemfert, C., Grubb, M., Köhler, J. (2006), Induced Technological Change: Exploring its Implications for the Economics of Athmospheric Stabilization: Synthesis Report from Innovation Modeling Comparison Project. The Energy Journal, Special Issue 2006, 57-107.

[8] Edmonds, J., Wise, M., Pitcher, H., Richels, R., Wigley, T., MacCracken, C. (1997), An Integrated Assessment of Climate Change and the Accelerated Introduction of Advanced Energy Technologies. Mitigation and Adaptation Strategies for Global Change 1, 311-39.

[9] den Elzen, M.G.J, Lucas, P.L. (2005), The FAIR model: A tool to analyse environmental and costs implication of regimes of future commitments. Environmental Modeling and Assessment 10, 115-134.

[10] den Elzen, M., Lucas, P.-A., van Vuuren, D. (2005), Abatement costs of post-Kyoto climate regimes. Energy Policy 33, 2138-2151.

[11] Frei, C.W., Haldi, P., Sarlos, G. (2003), Dynamic formulation of a top-down and bottom-up merging energy policy model. Energy Policy 31, 1017-1031.

[12] Gerlagh, R., van der Zwaan, B. (2003), Gross world product and consumption in a global warming model with endogenous technological change. Resource and Energy Economics 25, 35-57. 
[13] Gerlagh, R., van der Zwaan, B. (2004), Sensitivity Analysis of Timing and Costs of Greenhouse Gas Emissions Reduction. Climatic Change 65, 39-71.

[14] Guest, R.S., McDonald, I.M. (2007), Global GDP shares in the 21st century - An equilibrium approach. Economic Modelling 24, 859-877.

[15] Hamelinck, C. (2004), Outlook for advanced biofuels. Ph.D. thesis, University of Utrecht, The Netherlands.

[16] Höhne, N., Galleguillos, C., Blok, K., Harnisch, J., Phylipsen, D. (2003), Evolution of commitments under the UNFCCC: Involving newly industrial economies and developing countries, Research Report, UBA-FB 000412, Umweltbundesamt.

[17] Hourcade, J.-C., Jaccard, M., Bataille, C., Ghersi, F. (2006), Hybrid Modeling: New Answers to Old Challenges. The Energy Journal, Special Issue 2006, 1-12.

[18] Kainuma, M., Matsuoka, Y., Morita, T. (2003), Climate Policy Assessment: AsiaPacific Integrated Modeling. Springer-Verlag, Tokyo.

[19] Kriegler, E., Bruckner, T. (2004), Sensitivity of emissions corridors for the 21 st century. Climatic Change 66, 345-387.

[20] Kahouli-Brahmi, S. (2008), Technological learning in energy-environment-economy modelling : A survey. Energy Policy 36, 138-162.

[21] Kypreos, S., Bahn, O. (2003), A MERGE model with endogenous technological progress. Environmental Modeling and Assessment 19, 333-358.

[22] Leimbach, M., Toth, F. (2003), Economic development and emission control over the long term: The ICLIPS aggregated economic model. Climatic Change 56, 139-165.

[23] Löschel, A. (2002), Technnological Change in Economic Models of Environmental Policy: A survey. Ecological Economics 43, 105-126.

[24] McKibbin, W.J., Wilcoxen, P.J. (1999), The theoretical and empirical structure of the G-Cubed model. Economic Modelling 16, 123-148.

[25] Kouvaritakis, N., Soria, A., Isoard, S. (2000), Endogenous learning in world postKyoto scenarios: applications of the POLES model under adaptive expectations. International Journal of Global Energy Issues 14, 222-248.

[26] Manne, A.S., Mendelsohn, M., Richels, R. (1995), MERGE - A Model for Evaluating Regional and Global Effects of GHG Reduction Policies. Energy Policy 23, 17-34.

[27] Manne, A. S., Rutherford, T. (1994), International trade, capital flows and sectoral analysis: formulation and solution of intertemporal equilibrium models. In: Cooper, W. W. and Whinston, A. B. (eds.), New directions in computational economics, Kluwer Academic Publishers, Dordrecht, The Netherlands, 191-205. 
[28] Mas-Colell, A., Whinston, M.D., Green J.R. (1995), Microeconomic Theory. Oxford University Press, New York.

[29] Messner, S., Schrattenholzer, L. (2000), MESSAGE-MACRO: Linking an Energy Supply Model with a Macroeconomic Model and Solving It Interactively. Energy 25, 267-282.

[30] Nordhaus, W.D., Yang, Z. (1996), A Regional Dynamic General-Equilibrium Model of Alternative Climate-Change Strategies. American Economic Review 86, 741-765.

[31] Petschel-Held, G., Schellnhuber, H.J., Bruckner, T., Toth, F.L., Hasselmann, K. (1999), The tolerable windows approach: theoretical and methodological foundations. Climatic Change 41, 303-331.

[32] Penn World Tables (2007), Version 6.2, http://pwt.econ.upenn.edu/php-site/pwtindex.php

[33] Riahi, K., Grübler, A., Nakicenovic, N. (2007), Scenarios of long-term socioeconomic and environmental development under climate stabilization. Technological Forecasting and Social Change 74, 887-935.

[34] Rogner, H.H. (1997), An Assessment of World Hydrocarbon Resources. Annual Review of Energy and Environment 22, 217-262.

[35] Rose, A., Stevens, B. (1993), The efficiency and equity of marketable permits for $\mathrm{CO}_{2}$ emissions. Resource and Energy Economics 15, 117-146.

[36] Sanstad, A.H., Greening, L.A. (1998), Economic models for climate policy analysis: A critical discussion. Environmental Modeling and Assessment 3, 3-18.

[37] Takeshita, T., Yamaij, K. (2008), Important roles of Fischer-Tropsch synfuels in the global energy future. Energy Policy 36, 2773-2784.

[38] Vaillancourt, K., Loulou, R., Kanudia, A. (2008), The Role of Abatement Costs in GHG Permit Allocations: A Global Stabilization Scenario Analysis. Environmental Modeling and Assessment 13, 169-179.

[39] World Development Indicators (2005), World Bank. Washington, DC.

[40] Weyant, J. P. (2004), Introduction and overview. Energy Economics, 26, 501 - 515. 